\title{
IMPACT OF RAIN, SWELL, AND SEA SURFACE CURRENTS \\ ON THE ELECTROMAGNETIC BIAS IN GNSS-REFLECTOMETRY
}

\author{
Ali Ghavidel, Student Member IEEE, Adriano Camps, IEEE Fellow
}

Department of Signal Theory and Communications

Universidad Politécnica de Catalunya, Barcelona-Tech, and IEEC/UPC

Campus Nord, building D3, 08034 Barcelona, Spain.

Email: ali.ghavidel@tsc.upc.edu, camps@tsc.upc.edu

\begin{abstract}
In previous studies a method was devised to estimate the EM bias in bistatic GNSS-R altimetry (L-band) for a wind-driven sea surface spectrum. In the present study, the synthetic three-dimensional timeevolving wind-driven sea surface is also altered by rain, swell, or sea surface currents. The generated sea surface is illuminated by a Right Hand Circular Polarization (RHCP) L-band electromagnetic wave. Then, the scattered wave is computed from each facet in which the sea surface is discretized using the Physical Optics (PO) method. Finally, the EM bias is computed numerically under the presence of these three natural phenomena listed before. The impact of rain is a moderate decrease (in magnitude) of the EM bias due to the damping of the wind-driven waves, which is more significant as the wind speed increases. The impact of swell is a small increase (in magnitude) of the EM bias due to the increased sea surface roughness. The impact of currents can be either a moderate increase or decrease of the EM bias, depending on the sense of the current with respect to the wind.
\end{abstract}

\section{Introduction}

Nowadays, remote sensing using "free" signals of opportunity provides new chances for innovative Earth observation. Global Navigation Satellite Systems (GNSS) emit RHCP waves towards the Earth's surface continuously. The reflected waves contain valuable information from the Earth characteristics. The idea of using GNSS signals in remote sensing was first proposed in 1988 for scatterometry [1], and in 1993 for mesoscale ocean altimetry [2]. The EM bias is induced by the wave asymmetry (peaks and valleys), and it is an important error source in radar altimetry. Several studies to estimate the EM bias have been performed at C- and Ku-bands for nadir-looking, and off-nadir configuration scenarios by [311]. In previous works, the EM bias for a wind-driven sea surface was analyzed using the Kirchhoff Approximation of the Geometric Optics method [12]. Later, this model was refined using the Physical Optics method [13]. This method was validated using existing data at C- and Ku-bands, and then extended to L-band in bistatic configurations (GNSS-R), including the dependence with the wind speed, the incidence/scattering angles, and the azimuth angle. However, to authors' knowledge, the impact 
on the EM bias of rain, swell, and sea surface currents over the sea surface was not considered previously. This study addresses these issues.

Rain drops splashing on the sea surface induce changes in the surface roughness, that depend on the rain-rate intensity, and the drop size distribution (DSD). In this study, the log-Gaussian spectrum proposed in $[14,15]$ is used to generate the sea surface overlapped by rain-drops.

Swell is a series of mechanical propagating waves not generated by the immediate local wind, but by distant weather systems instead, where wind is blowing for a period of time over a given fetch. The swell spectrum can be modeled using a narrow-band Gaussian process by a two dimensional roughness spectrum [16], superimposed to the sea spectrum. In [16], the impact of swell on the scattering crosssection was investigated at L-band, and it was demonstrated that the scattering cross-section increased.

Finally, sea surface currents influence the Earth's climate system, by transporting massive amounts of heat. Near-surface currents alter the sea surface roughness and can affect the scattering processes significantly. The impact over the sea surface spectrum of the sea surface currents has been accounted for using Huang's model [17].

Since the impact of these perturbing effects is small or moderate, we are only interested in the deviations with respect to the wind-driven spectrum. These models have been successfully used in the past to compute the impact of rain, swell, and currents in the sea surface emissivity at L-band [18-20].

In this work, the scattering cross-section of the perturbed sea surface, is computed using the PO scattering technique (e.g. $[13,21])$, and the EM bias is numerically computed using the fundamental definition as the ratio of the average of the radar cross-section density $\left(\sigma^{0}\right)$ times the sea surface elevation $(\xi)$, divided by the average radar cross-section density [22]:

$$
\beta_{E M}=\frac{\left\langle\xi \sigma^{0}\right\rangle}{\left\langle\sigma^{0}\right\rangle}
$$

The computation of the EM bias is required to accurately predict the performance of upcoming GNSSR systems [23].

This document is organized as follows: Section 2 analyses the impact of rain on the EM bias, Section 3 the impact of swell, Section 4 the impact of surface currents, and finally Section 5 presents the conclusions. 


\section{Rain impact on the EM bias}

The impact of rain on the scattering cross-section was investigated at Ku-band [14], and it was demonstrated that the scattering cross-section was dependent on the rain-rate intensit. In [14], the rain spectrum was analyzed and it was proposed to have contributions from the ring-waves on the water, and from turbulence underneath the water surface. The rain-perturbed sea surface spectrum is can then be simulated by superimposing the rain-induced sea surface spectrum to the wind-driven one, and solving iteratively to satisfy some conditions [15]. The impact of heavy rainfall is a damping of the sea waves [24]. Figure 1 shows the wind-driven and the rain contributions to the composite sea surface height spectrum in the highest wavenumbers.

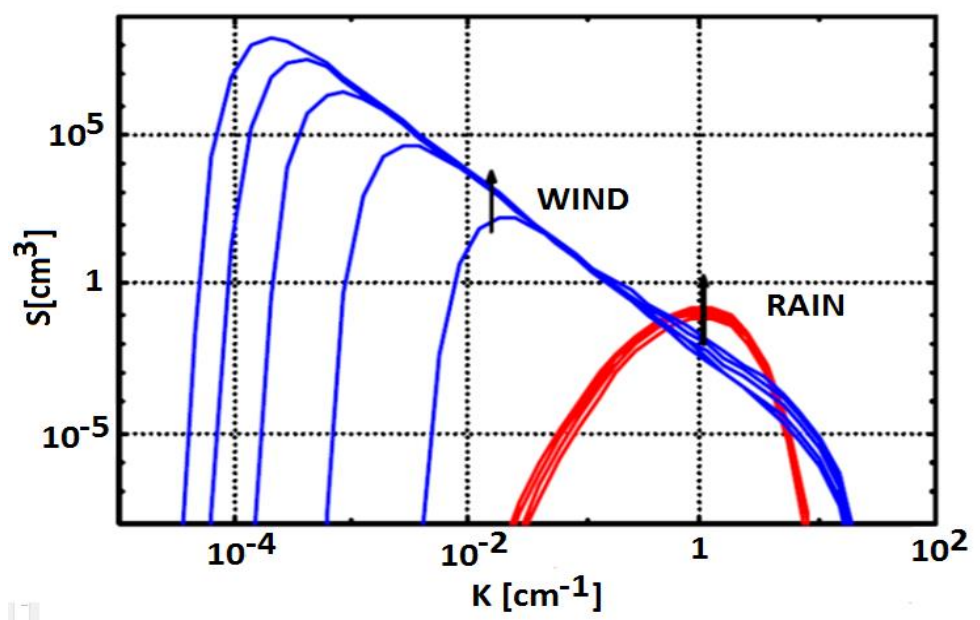

Fig. 1. Wind-induced sea surface spectrum for wind speeds $5,10,15$ and $20 \mathrm{~m} / \mathrm{s}$, and rain-induced sea surface spectrum for rain rates $20,40,60$ and $80 \mathrm{~mm} / \mathrm{h}$ (modified from [18]).

Then, a time-dependent $1000 \mathrm{~m} \times 1000 \mathrm{~m}$ sea surface $\left(\varepsilon_{r}=73+\mathrm{j} 57.5\right)$ is computed, so as to include the longest waves associated to the highest wind speed conditions, and discretized in $20 \mathrm{~cm}$ side patches. The incident electromagnetic wave illuminating the sea surface is then created: a RHCP wave at L-band $\left(f_{L 1}=1.57542 \mathrm{GHz}\right)$, which was actually pre-recorded using a GPS data-logger. The scattered wave from a rain-perturbed sea surface is finally computed using the PO method to obtain the scattering cross-section, as required by eqn. 1 .

The EM bias computed for $\theta_{i}=\theta_{s}=25^{\circ}, 35^{\circ}$ and $45^{\circ}$ are presented in Fig. 2, as a function of the wind speed without and with rain $(R=200 \mathrm{~mm} / \mathrm{h})$. Error bars indicate the $95 \%$ confidence level associated to the 10 Monte-Carlo simulations performed. As it seen, the EM bias is always smaller for rainperturbed sea surfaces because of the damping of the large sea waves. This effect becomes more important at high wind speeds. 


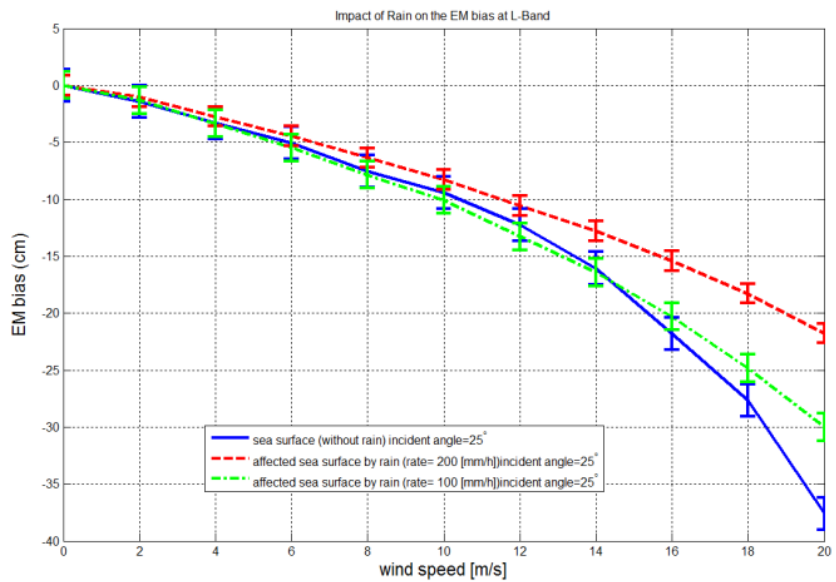

a)

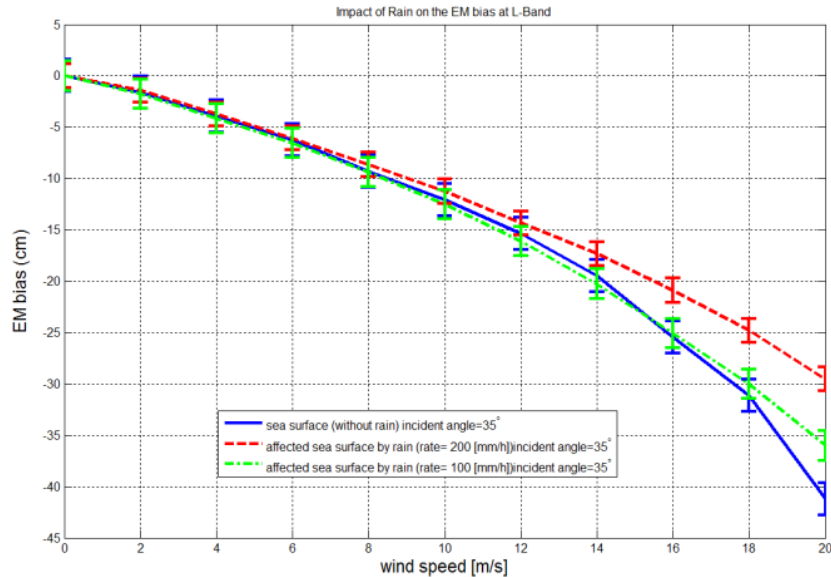

b)

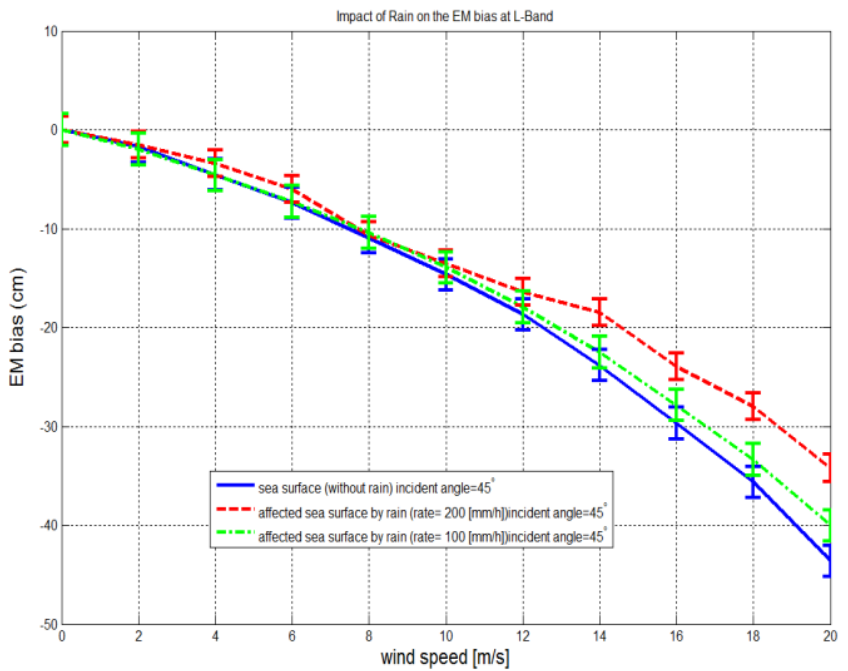

c)

Fig. 2. Estimated EM bias using [13] for the sea surface with and without rain: $R=0 \mathrm{~mm} / \mathrm{h}$ (blue), $R=100 \mathrm{~mm} / \mathrm{h}$ (green), and $R=200 \mathrm{~mm} / \mathrm{h}$, and incidence/scattering angles a) $\theta_{i}=\theta_{s}=25^{\circ}$, b) $\theta_{i}=\theta_{s}=35^{\circ}$, a) $\theta_{i}=\theta_{s}=45^{\circ}$. 


\section{Swell impact on the EM bias}

The swell of impact on the scattering cross-section was investigated using the two-scale model at $L, X$, and Ku bands [24, 25]. It was shown that the scattering cross-section was significantly affected by swell at L-band, although it was negligible at Ku-band [16].

Following [16], in this study the swell impact is modeled as a narrow-band Gaussian spectrum to the ocean spectrum:

$$
\Psi_{\text {swell }}\left(k_{x}, k_{y}\right)=\frac{\left\langle h^{2}\right\rangle}{2 \pi \sigma_{x} \sigma_{y}} \cdot \exp \left\{-\frac{1}{2}\left[\left(\frac{k_{x}-k_{x m}}{\sigma_{x}}\right)^{2}+\left(\frac{k_{y}-k_{y m}}{\sigma_{y}}\right)^{2}\right]\right\}
$$

where $\left\langle h^{2}\right\rangle$ is the height variance of the swell, $\sigma_{x}$ and $\sigma_{y}$ are the spectral standard deviations, and $k_{x m}$ and $k_{y m}$ are the spectral peak wave numbers of the swell in the $\mathrm{x}$ and $\mathrm{y}$ directions, respectively, which in general, are not coincident to the up-wind and cross-wind ones.

To illustrate this effect a swell with $\sqrt{\left\langle h^{2}\right\rangle}=4 \mathrm{~m}$, with a wavelength $\Lambda_{m}=400 \mathrm{~m}\left(k_{m}=2 \pi / \Lambda_{m}\right)$, and with $\sigma_{x}=\sigma_{y}=0.0025 \mathrm{~m}^{-1}$ is simulated. The computed EM bias affected by swell is shown in Fig. 3 . As it can be appreciated, the presence of swell produces an increase (in magnitude) of the EM bias. As interesting point is that, since the swell model includes very large quasi-sinusoidal waves, the impact is negligible at low wind speeds (sea surface spectrum has negligible skewness), and it is only noticeable for strong winds due to the change of the local slopes.

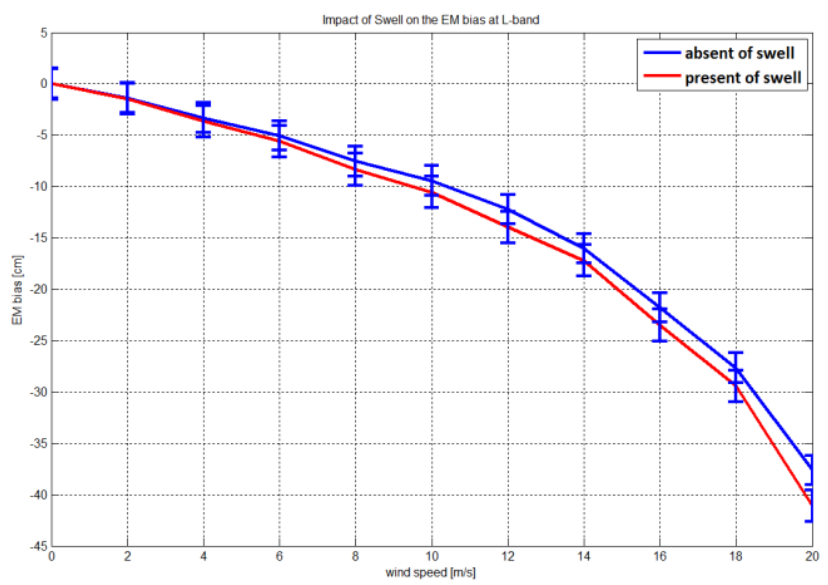

Fig. 3. EM bias at $\theta_{i}=\theta_{S}=25^{\circ}$ computed with and without a swell of $\left\langle h^{2}\right\rangle=4 \mathrm{~m} \mathrm{rms}, \Lambda_{m}=400 \mathrm{~m}$, and $\sigma_{x}=\sigma_{y}=0.0025 \mathrm{~m}^{-1}$. 


\section{Sea surface currents impact on the EM bias}

Ocean currents also affect the sea surface spectrum. When the current has the same direction and sense as the wind, the sea surface becomes less rough. On the contrary, when the current has the opposite sense (against the wind direction), the sea surface becomes rougher. In this study, the closedform derived by Huang et al. [17] is used:

$$
S(K)=\frac{a}{K^{3}} \cdot \frac{1}{\left(1+\frac{U_{\text {current }}}{c}\right)^{7}} \cdot \exp \left\{-\frac{0.74 \cdot g^{2}}{K^{2} \cdot U_{10}^{4} \cdot\left(1+\frac{U_{\text {current }}}{c}\right)^{4}}\right\},
$$

where $K$ is the wavenumber, $a=4.05 \cdot 10^{-3}, c$ is the waves' phase velocity, $U_{10}$ is the $10 \mathrm{~m}$ height wind speed, and $U_{\text {current }}$ is the current speed.

Figure 4 shows the impact of ocean currents in the EM bias as a function of the wind speed. When the current is positive (same direction as the wind), the EM bias decreases because of the reduced surface roughness, and when the current is negative (against the wind), the EM bias increases in magnitude, with a maximum increment of $\sim 5 \mathrm{~cm}$ at $U_{10}=20 \mathrm{~m} / \mathrm{s}$, and $\theta_{i}=\theta_{s}=25^{\circ}$.

Figure 4 shows, presence of the ocean current with opposite of wind direction is increased the EM bias as expected (because of roughness increment). It should be mentioned that by presence of ocean current, the EM bias is begging to increase from low wind speed to higher wind speeds. In addition, it shows, the current ocean with the same wind direction is decreased the EM bias.

\section{Conclusions}

The EM bias dependence on the wind speed and the incidence angle was studied in $[12,13]$ for a 2D sea surface and in [28] for a 1D sea surface. The impact on the EM bias of other natural phenomena influencing the sea surface roughness has been studied in this work for a bistatic configuration at L-band (GNSS-R system), as a function of the wind speed, and for different incidence/scattering angles.

The presence of heavy rainfall over the sea surface affects the EM bias, but this effect is only detectable at high wind speeds, and for large rain rates. At $\theta_{i}=\theta_{s}=25^{\circ}$, the EM bias decreases (in magnitude) by $\sim 5 \mathrm{~cm}$ for $U_{10}=20 \mathrm{~m} / \mathrm{s}$ and $R=200 \mathrm{~mm} / \mathrm{h}$.

The impact of swell over the ocean surface is an increase of the EM bias values, although this effect is weak, and only noticeable $(\sim 2-3 \mathrm{~cm})$ for high wind speeds $\left(U_{10}=20 \mathrm{~m} / \mathrm{s}\right)$ and large swells (4 m rms height). 


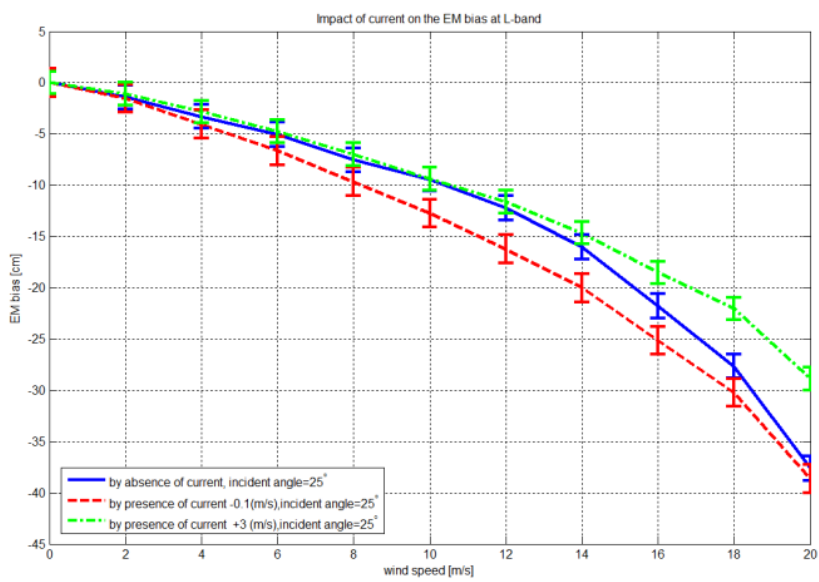

a)

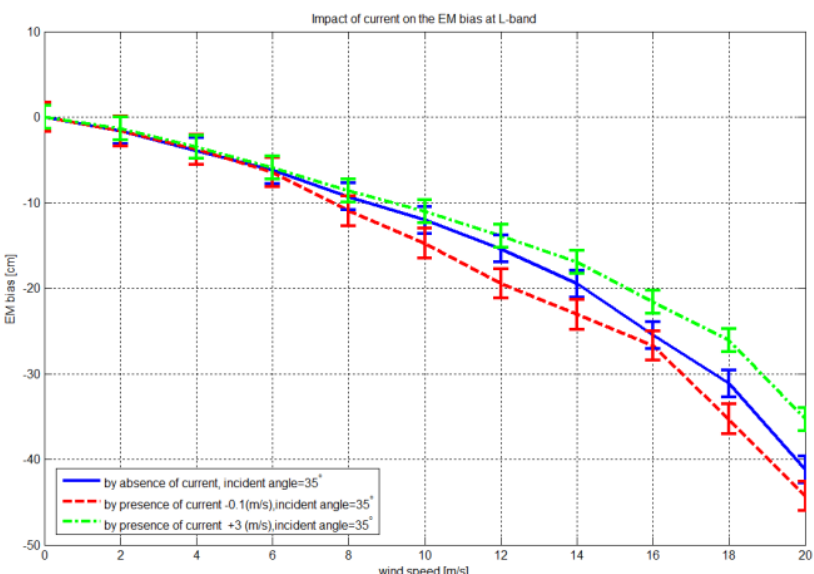

b)

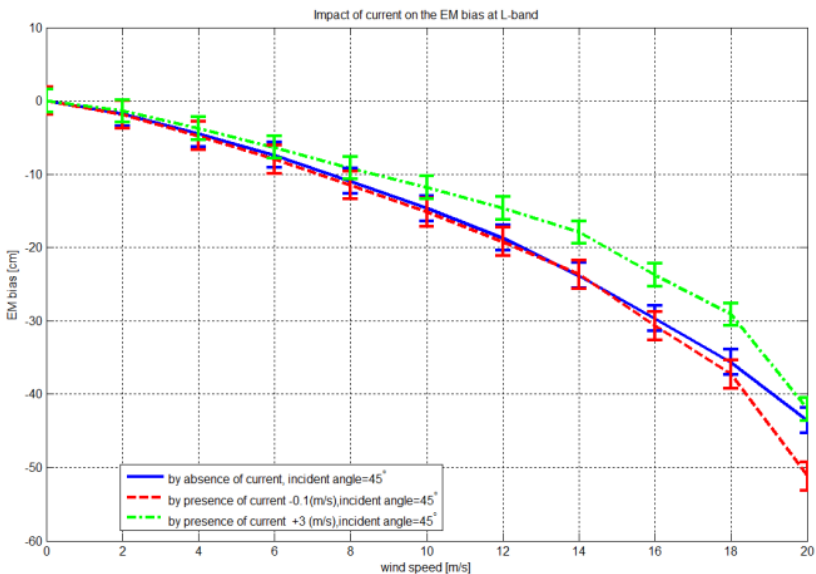

c)

Fig. 4. EM bias as a function of the wind speed computed without sea surface currents, and with currents of $U_{\text {current }}=+3 \mathrm{~m} / \mathrm{s}$ (green, same direction as wind), and $U_{\text {current }}=-0.1 \mathrm{~m} / \mathrm{s}$ (red, opposite direction to wind), for incidence angles: a) $\theta_{i}=\theta_{s}=25^{\circ}$, b) $\theta_{i}=\theta_{s}=35^{\circ}$, and c) $\theta_{i}=\theta_{s}=45^{\circ}$. 
Finally, the effect of surface currents can be either an increase or a decrease of the EM bias, depending if the current is against the wind or if it has the same direction and sense. The presence of currents $\left(U_{\text {current }}=-0.1 \mathrm{~m} / \mathrm{s}\right)$ with opposite direction to the wind increases the EM bias for all incidence angles, and particularly at higher wind speeds. In contrary, while the sea surface has current $\left(U_{\text {current }}=+3 \mathrm{~m} / \mathrm{s}\right)$ by same wind direction, the EM bias is decreased.

Since these natural effects produce a non-negligible variability of the EM bias ( $~ 50 \%$ change), it is important to account for them in order to make a good estimate of this residual error in GNSS-R altimetry budgets.

\section{Acknowledgement}

This work has been support by the Spanish National Research project AYA2011-29183-C02-01 from the Ministry of Economy and Competitiveness.

\section{References}

[1] C. D. Hall and R. A. Cordey, "Multistatic scatterometry," IEEE nternational Geosci. Remote Sens. Symp. Remote Sens. Symp., vol. 1, pp. 561-562, 1988.

[2] M. Martin-Neira, "A Passive Reflectometry and Interferometry System (PARIS): application to ocean altimetry," ESA J, pp. 331-355, 1993.

[3] B. S. Yaplee, A. Shapiro, D. L. Hammond, B. D. Au, and E. A. Uliana, "Nanosecond radar observations of the ocean surface from a stable platform," IEEE Trans. Geosci. Electron., vol. 9, no. 3, 1971.

[4] F. C. Jackson, W. T. Walton, N. Goddard, and P. L. Baker, "Aircraft and satellite measurement of ocean wave directional spectra using scanning-beam microwave radars," vol. 90, pp. 987-1004, 1985.

[5] M. A. Srokosz, "On the joint distribution of surface elevation and slopes for a nonlinear random sea, with an application to radar altimetry," J. Geophys. Res. Ocean., vol. 91 C1, pp. 995-1006, 1986.

[6] R. E. Glazman, A. Fabrikant, and M. A. Srokosz, "Numerical analysis of the sea state bias for satellite altimetry," J. Geophys. Res. Ocean., vol. 101, pp. 3789-3799, 1986.

[7] E. J. Walsh, F. C. Jackson, D. E. Hines, C. Piazza, L. G. Hevizi, D. J. Mclaughlin, R. E. Mcintosh, R. N. Swift, J. F. Scott, and J. K. Yungel, "Frequency dependence of electromagnetic bias in radar altimeter sea surface range measurements," J. Geophys. Res. Ocean., vol. 96, pp. 20571-20583, 1991.

[8] L. G. Hevizi, E. J. Walsh, R. E. McIntosh, D. Vandemark, D. E. Hines, R. N. Swift, and J. F. Scott, "Electromagnetic bias in sea surface range measurements at frequencies of the TOPEX/POSEIDON satellite," IEEE Trans. Geosci. Remote Sens., vol. 31, pp. 376-388, 1993.

[9] T. Elfouhaily, D. R. Thompson, B. Chapron, and D. Vandemark, "Improved electromagnetic bias theory," J. Geophys. Res. Ocean., vol. 105, pp. 1299-1310, 2000.

[10] F. W. Millet, K. F. Warnick, and D. V. Arnold, "Electromagnetic bias at off-nadir incidence angles," J. Geophys. Res., vol. 110, no. C9, pp. 1-13, 2005. 
[11] F. W. Millet, K. F. Warnick, J. R. Nagel, and D. V Arnold, "Physical optics-based electromagnetic bias theory with surface height - slope cross-correlation and hydrodynamic modulation," IEEE Trans. Geosci. Remote Sens., vol. 44, no. 6, pp. 1470-1483, 2006.

[12] A. Ghavidel, D. Schiavulli, and A. Camps, "A numerical simulator to evaluate the electromagnetic bias in GNSS-R altimetry," in IEEE Int. Geoscience and Remote Sensing Symposium, 2014, pp. 4066-4069, 13-18 July 2014, Quebec, Canada.

[13] A. Ghavidel, D. Schiavulli, and A. Camps, "Numerical computation of the electromagnetic bias in GNSS-R altimetry," (under review) 2015.

[14] L. F. Bliven, P. W. Sobieski, and C. Craeye, "Rain generated ring-wave: measurements and modeling for remote sensing," Int. J. Remote Sens., vol. 18, no. 1, pp. 221-228, 1997.

[15] C. Craeye, P. W. Sobieski, and L. F. Bliven, "Scattering by artificial wind and rain roughened water surfaces at oblique incidences," Int. J. Remote Sens., vol. 18, no. 10, pp. 2241-2246, 1997.

[16] S. Durden and J. Vesecky, "A physical radar cross-section model for a wind-driven sea with swell," IEEE J. Ocean. Eng., vol. 10, no. 4, pp. 445-451, 1985.

[17] N. E. Huang, D. T. Chen, C.-C. Tung, and J. R. Smith, "Interactions between Steady Won-Uniform Currents and Gravity Waves with Applications for Current Measurements," J. Phys. Oceanogr., vol. 2, no. 4, pp. 420-431, 1972.

[18] A. Camps, M. Vall-Ilossera, J. Miranda, N. Duffo, "Emissivity of the sea surface roughened by rain: simulation results," Geoscience and Remote Sensing Symposium, 2001. IGARSS '01. IEEE 2001 International, vol.5, no., pp.2433,2435 vol.5, 2001

[19] J. Miranda, M. Vall-llossera, A. Camps, N. Duffo, "Sea surface emissivity at L-band: swell effects," Geoscience and Remote Sensing Symposium, 2002. IGARSS '02. 2002 IEEE International , vol.5, no., pp.2623,2625 vol.5, 2002

[20] A. Camps, M. Vall-llossera, J. Miranda, J. Font, "Sea surface brightness temperature at L-band: impact of surface currents," Geoscience and Remote Sensing Symposium, 2004. IGARSS '04. Proceedings. 2004 IEEE International, vol.5, no., pp.3481,3484 vol.5, 20-24 Sept. 2004

[21] M. P. Clarizia, S. Member, C. Gommenginger, M. Di Bisceglie, C. Galdi, and M. A. Srokosz, "Simulation of L-Band Bistatic Returns From the Ocean Surface : A Facet Approach With Application to Ocean GNSS Reflectometry," IEEE Trans. Geosci. Remote Sens., vol. 50, no. 3, pp. 960-971, 2012.

[22] T. Elfouhaily, D. Thompson, D. Vandemark, and B. Chapron, "Weakly nonlinear theory and sea state bias estimations," Journal of Geophysical Research, 1999.

[23] A. Camps, H. Park, E. Valencia I Domenech, D. Pascual, F. Martin, A. Rius, S. Ribo, J. Benito, A. Andres-Beivide, P. Saameno, G. Staton, M. Martin-Neira, S. Daddio, and P. Willemsen, "Optimization and performance analysis of interferometric GNSS-R altimeters: Application to the PARIS IoD mission," IEEE J. Sel. Top. Appl. Earth Obs. Remote Sens., vol. 7, no. 5, pp. 1436-1451, 2014.

[24] M. J. Manton, “On the attenuation of sea waves by rain," Geophys. Fluid Dyn., vol. 5, no. 1, pp. 249-260, 1973.

[25] J. W. Wright, "A new model for sea clutter," Antennas Propagation, IEEE Trans., vol. 16, pp. 217-223, 1968.

[26] F. Bass, I. Fuks, A. Kalmykov, I. Ostrovsky, and A. Rosenberg, "Very high frequency radiowave scattering by a disturbed sea surface Part I: Scattering from a slightly disturbed boundary," IEEE Trans. Antennas Propag., vol. 16, 1968.

[27] E. Bahar, "Scattering cross sections for composite random surfaces: Full wave analysis," Radio Sci., vol. 16, no. 6, pp. 1327-1335, 1981.

[28] J. Park, J. T. Johnson, S. T. Lowe, "A study of the electromagnetic bias in GNSS-R Altimetry," International Geoscience and remote Sensing Symposium, Québec, Canada, July 13-18, 2014. 